\title{
Team Learning, Transactive Memory System and Team Performance: A Longitudinal Study Based on the IMOI Approach
}

\author{
(C) Higher Education Press and Springer-Verlag 2010
}

\begin{abstract}
This study examines how team learning behaviors transfer into team effectiveness, and analyzes the dynamic mechanism of team learning within a time series framework. 99 teams were recruited as our initial sample at the first stage, and 55 teams were traced at the second stage. We employed the input-mediator-output-input (IMOI) approach as proposed by Ilgen et al. (2005), instead of the traditional input-process-output (I-P-O) model in industrial and organizational psychology. Results show that the mediating effect of transactive memory system (TMS) on the relationship between team learning and performance is significant at both stages, which means TMS can adequately account for how team learning influences team performance as a mediator. Team performance, as an output received at the end of stage one, also acts as an important input variable at stage two, which in turn positively influences the subsequent team learning process. The circular causal model based on path analysis shows that the IMOI approach can be used to explain organizational mechanisms better than the classic I-P-O approach; the result is consistent with the new trends within the team relevant IO psychological understanding. Findings suggest that developing and maintaining a TMS is critical to achieving team outputs under a team learning setting. In addition, performance evaluation and feedback are also important factors within team learning processes. We argue that organizational behavior research based on an IMOI approach would have
\end{abstract}

Translated from Xinli Xuebao 心理学报 (Acta Psychologica Sinica), 2009, 41(7): 639-648

Shenjiang Mo

School of Management, Zhejiang University, Hangzhou 310058, China

E-mail: moshenjiang@zju.edu.cn

Xiaoyun Xie ( $\square)$

School of Management, Zhejiang University, Hangzhou 310058, China

E-mail: xiexy@zju.edu.cn 
more generalizability and ecological validity than the traditional I-P-O model.

Keywords team learning, transactive memory system, team performance, input-mediaton-output-input (IMOI), longitudinal design

\section{Introduction}

Over the past two decades, research on team learning behaviors has significantly increased with the growing popularity of teamwork patterns. Team researchers have paid close attention to team learning, which is essential to team processes and effectiveness (Edmondson, 1999, 2002). A number of excellent team learning studies have appeared recently, providing us with important insights of team learning effectiveness (e.g., Bruhn and Gibson, 2006), innovation (Wong, 2004), knowledge management and other organizational behavioral characteristics.

While the antecedents and consequences of team learning process have been examined extensively, little attention has been given to the question that how team learning behaviors successfully transfer into team effectiveness. Recent organizational learning studies emphasized team learning is a multi-stage and dynamic process. However, we notice that few studies have been done with a longitudinal research design in order to describe the process mechanism. Therefore, this paper responds to this need by providing an empirical answer to further explain the mechanism for effective team learning.

\subsection{Team Learning and Performance}

Team learning is an interpersonal process in which a team obtains team knowledge referring to task skills and group background. Specifically, the basic processes of team learning are sharing (learn new knowledge, routine, and behaviors), storage (create distributed knowledge memory system), and retrieval (access knowledge for subsequent inspection or use) (Wilson, Goodman and Cronin, 2007). The interaction of these three processes facilitates team knowledge acquisition and distribution.

Over the last two decades, many scholars have examined the relationship between team learning and performance from various theoretical perspectives. Some studies proposed that knowledge acquisition capability can be improved by team learning behaviors. For example, based on results of a qualitative study on 12 real teams, Edmondson (2002) highlighted that promotion of internal communication among team members can facilitate the process of maintaining new knowledge and routine. This conclusion is consistent with Offenbeek's (2001) viewpoint in a field study with a sample of 26 student teams. Focusing on 
new product developing teams, Lynn also proposed that customer needs can be precisely identified by frequent internal learning and communicating behaviors (Lynn, Skov and Abel, 1999). On the other hand, scholars argued that team learning improves the efficiency of knowledge processing. For instance, using brainstorm teams as research sample, Paulus and Yang (2000) found that high frequency exchange of different knowledge among team members can effectively improve the ability of knowledge acquisition and utilization, to achieve high innovative performance. Their findings were also well supported by Wong's (2004) research arguments.

The studies reviewed above have provided insights of the close relationship between team learning and performance. However, they paid little attention to the mechanism in the process that specific learning behaviors transfer into team effectiveness. Meanwhile, as several recent studies have showed, team learning does not always directly lead to change in performance (Liang, Moreland and Argote, 1995; Lewis, 2003). Therefore, team-level constructs should be identified as the mechanism for effective learning process (Lewis, 2003; Lewis, 2004).

\subsection{Mediating Effect on Team Learning and Performance: A Theoretical Approach Based on the Transactive Memory System (TMS)}

Guzzo and Dickson (1996) conducted a comprehensive review on the literature of performance mechanism of team learning. As a conclusion, they pointed out that work enthusiasms, internal cohesion and social cognitive consistency are several key factors for learning effectiveness research. However, there is still a need for greater investigation into how these constructs facilitate the process of team learning (Wilson, Goodman and Cronin, 2007; Ilgen et al., 2005). In other words, the intermediate mechanism of continuous team learning process still needs much more effort in future research (Bruhn and Gibson, 2006). Based on this approach, psychologists carried out a series of attempts. For example, Polzer (2002) conducted a longitudinal study with a sample of 83 teams. His findings suggested that interpersonal congruence is a meaningful mediator in the relationship between team learning and performance. Sivasubramaniam, Murry and Jung's (2002) study described the output mechanism of learning process by applying team potency as a mediator. Besides, with a team development perspective, McCarthy and Garavan (2008) interpreted output mechanism in another way that the learning process is mediated by team cohesion. Although empirical studies discussed above have identified several mediating constructs of the team learning process, none of them revealed how team members work interdependently in order to complete the team task (Zhang, Hempel, Han and 
Qiu, 2006). Therefore, transactive memory system (TMS), which is particularly relevant for understanding team knowledge processes, was introduced into team learning research (Lewis, 2003; Zhang and Xiong, 2007; Zhang and Xiong, 2008).

Wegner (1987) first introduced the concept of TMS as a way to understand how couples coordinate to solve information problems. He argued that TMS is a combination of the knowledge possessed by each individual and a collective awareness of who knows what (Wenger, 1987). It provides individuals with access to a level of knowledge that no member could hope to remember (Austin, 2003). Thus, it is a collective memory system for encoding, storing, retrieving, and communicating group knowledge, which can significantly improve team's knowledge processing capability by recognizing each member's specific expertise (Zhang and Xiong, 2007). Based on a comprehensive review and a series of empirical studies, Lewis (2003, 2004) suggested that the TMS construct with three dimensions, reflect the specialization, credibility, and coordination manifestations.

Based on Wenger's TMS definition, several scholars have made effort on verifying the TMS constructs and their effectiveness. For example, Liang et al. (1995) designed an experimental study with laboratory work teams, in which members were taught to assemble transistor radios. Their results indicated that team training and communicating can positively improve team performance primarily by creating TMS among team members. Using similar experimental training conditions, Moreland and Myaskovs (2000) provided further evidence on the potential benefits of TMS for team performance. They argued that TMS not only mediates the relationship between training behaviors and outcomes, but also improves the inter-personal communication process. Lewis and his colleagues offered a more systematical explanation for the positive effects of TMS on team performance. Conceptualizing TMSs as learning systems, they suggested that a TMS helps members learn, both individually and collectively, as well as affect team knowledge transfer to produce sustained performance (Lewis, 2003; Lewis, 2004; Lewis, Lange and Gillis, 2005). Several recent studies on TMS (Jarenpaa and Majchrzak, 2008; Todorova, Arogte and Reagans, 2008) concluded that effectiveness of knowledge sharing among team members is dependent on the intensity of internal TMS. In addition, Zhang et al.'s (2007) empirical study with high-tech work teams in the Chinese culture context also proved the mediating role of TMS in the relationship between team characteristics and effectiveness. In light of the close link between training behaviors and knowledge learning and transfer, we propose that TMS is the mediating mechanism in the team learning process. 


\subsection{New Development of Team Research Paradigm: From I-P-O to IMOI}

Applying the traditional input-process-output model (I-P-O model), previous team learning research tried hard to investigate the relationship between antecedents (i.e., communication, goal setting, and role assignment) and effectiveness (i.e., performance, satisfaction, and cohesion) of learning performance. However, over the past several years, more attention has been paid to the mediating process that explains why certain inputs affect team effectiveness and viability. Thus, the utility of one-way I-P-O causal model as a guide to empirical research fails to capture the emerging consensus about teams as complex, adaptive, and dynamic systems (Ilgen et al., 2005). Moreland and Myaskovskey (2000) argued that the I-P-O sequence is insufficient for characterizing team behaviors. Therefore, the ecological validity of previous studies with an I-P-O sequence is challenged because of ignoring the dynamic circular causal relationship. As an alternative approach, Marks et al. (2001) proposed a recurring phase model (RP model) which suggests that I-P-O model appears repeatedly in time sequence.

As a symbolic theory, Ilgen et al.'s (2005) work comprehensively illustrated the necessity and feasibility of research pattern transition from I-P-O model to IMOI (input-mediator-output-input) model.

Ilgen et al. proposed that, "first, many of the mediational factors that intervene and transmit the influence of inputs to outcomes are not processes. Second, an I-P-O framework limits research by implying a single-cycle linear path from inputs through outcomes, even though the authors of the classic works clearly stipulated the potential for feedback loops. Indeed, more recent research has examined traditional 'outputs' like team performance and treated them as inputs to future team process and emergent states." Accordingly, they used an alternative IMOI model instead of the traditional I-P-O model, substituting "M" for "P" to reflect the broader range of mediators or moderators, and adding the extra "I" at the end of the model to explicitly invoke the notion of cyclical causal feedback. Many scholars have provided their viewpoints on this IMOI model, such as Burke, Stagl, Salas, Pierce and Kendall (2006) and Langfred (2007). Based on this new approach, Tasa et al. (2007) found that previous stage performance is also an input of the following team processes in their study on the evolution of team dynamics.

Lewis, Lange and Gillis (2005) first proposed an interactive TMS-learning framework which suggests that team learning is a multi-stage, circular continuous process. However, we notice that their framework only explains the effect of previous TMS on the following learning process. There is no specific consideration of the effectiveness of team performance which is the final output 
of a single learning process in this framework. Previous studies have showed that team performance feedback is positively associated with knowledge sharing and accumulating (Ryan, 2004). For instance, results of experimental studies done by Hisrt, Luckett and Trotman (1999) showed that team members can better understand and use work-related knowledge with positive performance feedback. Goodman, Wood and Hendrickx (2004) also found that detailed performance feedback facilitates team knowledge learning and transfer. In addition, from a diversity perspective, Meyvis and Cooke (2007) concluded that multi-source performance feedback contributes to effective learning and group decision-making. Therefore, we argue that performance feedback as output of a single learning process has a significant impact on the input of the following learning stage in a time sequence. It is also noted that several Chinese scholars, such as Chen and Ma (2000) also made great progress in introducing a circular model into organizational learning studies to better understand the continuous learning process in the Chinese cultural context.

This study intends to further develop the team learning framework proposed by Lewis et al. (2005), who suggested that TMS is formed by team learning at stage one and it affects the following learning process at stage two. Based on the framework and according to the IMOI model or Marks et al.'s (2001) RP model, we argue that TMS does not directly influence the following team learning process, but through the mediating effect of performance. Briefly, based on the IMOI (input-mediator-output-input) model, this study aims to examine a circular causal framework of learning-TMS-performance.

Thus, we propose the following two hypotheses:

H1 TMS mediates the relationship between team learning and performance.

H2 Circular causal model of team learning effectiveness follows the IMOI approach. Team performance, as an output received at the end of stage one, also acts as an important input variable at stage two, which in turn positively influences the following team learning process.

\section{Methods}

\subsection{Sampling and Data Collection}

Data were collected from a startup business plan competition held in a comprehensive university in China. Each team was requested to have one leader and 2-7 members, worked together for 6 months, and finally completed a business plan as a team output. In total, 112 teams participated in this competition.

Basic team information, including team size, gender, and major of team 
members, was first collected from the organizer. The team leader and members of each team completed leader and member questionnaires, respectively.

At the first stage, the sample size comprised 99 teams, where the response rate was $88.39 \%$. Among the members, $58.5 \%$ were male, and $45.9 \%$ majored in science and engineering. The average team size ranged from 3 to 8 people (mean $=5.02$ ). After three months, we traced the initial samples and obtained 55 teams at the second stage, resulting in a response rate of $87.3 \%$. At this point, $52.0 \%$ were male, and $46.4 \%$ majored in science and engineering. The average team size also ranged from 3 to 8 people $($ mean $=6.07)$.

\subsection{Measures}

\subsubsection{Team Learning}

Wong's (2004) scale was adapted to measure team learning. According to Wilson et al.'s (2007) definition of team learning, there is a knowledge storage process in addition to knowledge sharing and retrieval. Thus, we added three new items of knowledge storage according to Wilson et al.'s (2007) description. The sample items of the 11-item scale were "we discuss to figure out the feasibility of our project" and "we reflect on our past experience and discussion results." We used a five-point Likert-type response format $(1=$ strongly disagree; $5=$ strongly agree). The original questionnaires were in English. Therefore, we invited a professor and two doctorial students majored in management, to comparatively study both the original and Chinese versions.

\subsubsection{Transactive Memory System}

We applied Lewis's (2003) TMS scale to assess TMS, and also took Zhang et al.'s (2006) revised scale as reference. The 15-item scale included three dimensions, specialization, credibility, and coordination. The sample items were "team members know which members have expertise in specific areas." A five-point Likert-type response format $(1=$ strongly disagree; $5=$ strongly agree $)$ was used.

\subsubsection{Team Performance}

In order to minimize common method bias, we used external evaluation scores as team performance criterion in this study. Specifically, we used an average team performance score given by three experts, which ranged from 1 (extremely dissatisfied) to 5 (extremely satisfied). 


\subsubsection{Control Variables}

We included team size and initial familiarity of team members as control variables in hypotheses testing. We controlled these two variables because previous research has demonstrated that expansion of team size can cause social loafing effect (Bruhn and Gibson, 2006), and familiar members are more likely to have a variety of experiences together that give them a more accurate view on the content, credibility, and depth of a members' expertise (Lewis, 2004). We also applied one item "we know each other and have teamwork experience before" and a five-point Likert-type response format $(1=$ strongly disagree; $5=$ strongly agree) to measure team member familiarity.

\subsection{Aggregation of Individual to Team Measures}

The interrater agreement index, $r_{\mathrm{wg}}$ (James, Demaree and Wolf, 1984), and the intraclass correlation coefficient, ICC (Bliese, 1998a) were used to test whether individual members' scores for the team-level variables could be aggregated to the team. The mean $r_{\mathrm{wg}}$ was 0.83 and 0.84 for the two stages of team learning, 0.88 and 0.90 for TMS, respectively, which demonstrated high within-team agreement of these constructs. Besides, the ICC (1) (James, 1982) was 0.22 and 0.28 for the two stages of team learning, 0.15 and 0.13 for TMS, the ICC (2) (Bliese, 1998b) was 0.75 and 0.81 for two the stages of team learning, 0.71 and 0.64 for TMS. Overall, these results provided strong evidence of adequate within-team agreement, thereby supporting the aggregation of the bi-teammate data to the team level at both stages.

\section{Results}

\subsection{Measures Assessment and Descriptive Statistics}

Because modified scales were used in this study, both exploratory factor analysis (EFA) and confirmatory factor analysis (CFA) were conducted on the multi-item measures, team learning, and TMS. A principal axis factoring and direct oblimin rotation EFA was conducted on the team learning measure. Results of the EFA revealed that three factors with eigenvalues greater than one. All 10 items loaded as expected, except the $2^{\text {nd }}$ item. The scale reliability could increase from 0.78 to 0.82 by deleting this item according to reliability analysis results (Cronbach's alpha).

For the TMS scale, the EFA results supported Lewis's (2003) three-dimension model. However, the coefficient of $9^{\text {th }}$ and $15^{\text {th }}$ items was relatively low. After we dropped these two items, the scale reliability significantly improved from 0.79 to 
0.84. A CFA was conducted to verify the factor structure of the 13-item scale. Findings showed that the measurement model was a reasonable fit $\left(\chi^{2} / d f=1.44<\right.$ 2 , CFI $=0.94$, RMSEA $=0.067$ ).

Table 1 reports the descriptive statistics (i.e., means, standard deviations), intercorrelation coefficients, and reliability coefficients of these measures in this study.

Table 1 Means, Standard Deviations, Correlations and Reliabilities

\begin{tabular}{lcccccccccc}
\hline & Mean & SD & 01 & 02 & 03 & 04 & 05 & 06 & 07 & 08 \\
\hline $\begin{array}{l}\text { 01. Team } \\
\text { size }\end{array}$ & 6.07 & 1.27 & - & & & & & & & \\
02. Initial & 3.57 & 1.10 & 0.11 & - & & & & & & \\
$\quad$ familiarity & & & & & & & & \\
03. TL1 & 3.96 & 0.57 & 0.24 & $0.32^{*}$ & $\mathbf{( 0 . 8 2 )}$ & & & & & \\
04. TMS1 & 4.06 & 0.46 & 0.08 & 0.24 & $0.29^{*}$ & $\mathbf{( 0 . 8 4 )}$ & & & & \\
05. TP1 & 3.79 & 0.31 & 0.08 & 0.01 & $0.27^{*}$ & $0.39^{* *}$ & - & & & \\
06. TL2 & 3.90 & 0.54 & 0.10 & 0.13 & 0.15 & $0.27^{*}$ & $0.30^{*}$ & $\mathbf{( 0 . 8 4 )}$ & & \\
07. TMS2 & 4.05 & 0.40 & 0.09 & 0.03 & $0.27^{*}$ & $0.30^{*}$ & 0.19 & $0.55^{* *}$ & $\mathbf{( 0 . 7 4 )}$ & \\
08. TP2 & 3.79 & 0.35 & -0.07 & -0.14 & 0.18 & 0.11 & $0.49^{* *}$ & $0.27^{*}$ & $0.35^{* *}$ & - \\
\hline
\end{tabular}

Note: a. Cronbach's Alphas appear on the diagonal, with parameters. $N=55$.

b. TL means team learning, TMS means transactive memory system, TP means team performance.

c. * indicates significant at level $0.05, * *$ indicates significant at level 0.01 .

As expected, team learning was significantly related to TMS and team performance at the same time point. But surprisingly, there is no significant relationship between the two stages of team learning. One possible explanation is that team learning at stage two is mainly influenced by the outcomes at stage one, as suggested by Ilgen et al. (2005).

\subsection{Hypotheses Tests}

H1 proposes that TMS mediates the relationship between team learning and performance. Hierarchical regression results in Table 2 reveal that the mediating effect of TMS on the relationship between team learning and performance is significant at both stages, which means the TMS can adequately interpret how team learning influences team performance as a mediator. Hence, H1 is supported.

$\mathrm{H} 2$ puts that circular causal model of team learning effectiveness follows the IMOI model. Team performance, as an output received at the end of stage one, also acts as an important input variable at stage two, which in turn positively influences the following team learning process. Controlling covariates of the 
variable measurements at the two time points, we used LISREL 8.7 to conduct further path analysis. The results are shown in Fig. 1.

Table 2 Regression Results ${ }^{\text {a }}$

\begin{tabular}{|c|c|c|c|c|c|c|c|c|c|}
\hline \multirow[b]{2}{*}{ Variables } & \multirow[b]{2}{*}{ Steps } & \multicolumn{4}{|c|}{$\mathrm{DV}=\mathrm{TP} 1$} & \multicolumn{4}{|c|}{$\mathrm{DV}=\mathrm{TP} 2$} \\
\hline & & $M 1$ & $M 2$ & M3 & M4 & $M 1$ & $M 2$ & $M 3$ & M4 \\
\hline \multirow{3}{*}{$\begin{array}{l}\text { Control } \\
\text { variables }\end{array}$} & Team size & -0.08 & -0.16 & -0.10 & -0.16 & -0.04 & -0.04 & -0.06 & -0.06 \\
\hline & $\begin{array}{l}\text { Initial } \\
\text { familiarity }\end{array}$ & 0.02 & -0.09 & -0.08 & -0.15 & -0.04 & -0.04 & -0.05 & -0.05 \\
\hline & $\begin{array}{l}\text { Team } \\
\text { performance } 1\end{array}$ & & & & & $0.27^{*}$ & $0.27^{*}$ & $0.26^{*}$ & $0.26^{*}$ \\
\hline \multirow{4}{*}{$\begin{array}{l}\text { Predictor } \\
\text { variables }\end{array}$} & $\begin{array}{l}\text { Team } \\
\text { learning } 1\end{array}$ & & $0.38^{*}$ & & 0.29 & & & & \\
\hline & TMS 1 & & & $0.44^{* *}$ & $0.38^{*}$ & & & & \\
\hline & $\begin{array}{l}\text { Team } \\
\text { learning } 2\end{array}$ & & & & & & $0.33^{* *}$ & & 0.13 \\
\hline & TMS 2 & & & & & & & $0.42^{* *}$ & $0.35^{* *}$ \\
\hline$R^{2}$ & & 0.01 & 0.13 & 0.19 & 0.25 & 0.02 & 0.07 & 0.13 & 0.17 \\
\hline$\Delta R^{2}$ & & 0.01 & $0.12^{*}$ & $0.18^{* *}$ & $0.24^{* *}$ & 0.02 & $0.05^{*}$ & $0.11^{* *}$ & $0.14^{* *}$ \\
\hline$F$ & & 0.13 & 2.05 & $3.19^{*}$ & $3.41^{*}$ & 0.50 & 1.33 & $1.54^{* *}$ & $2.01^{* *}$ \\
\hline$\Delta F$ & & 0.13 & $5.85^{*}$ & $9.25^{* *}$ & $6.65^{* *}$ & 0.50 & $4.26^{*}$ & $7.53^{* *}$ & $6.89^{* *}$ \\
\hline
\end{tabular}

Note: a. TL means team learning, TMS means transactive memory system, TP means team performance.

b. * indicates significant at level $0.05, * *$ indicates significant at level 0.01 .

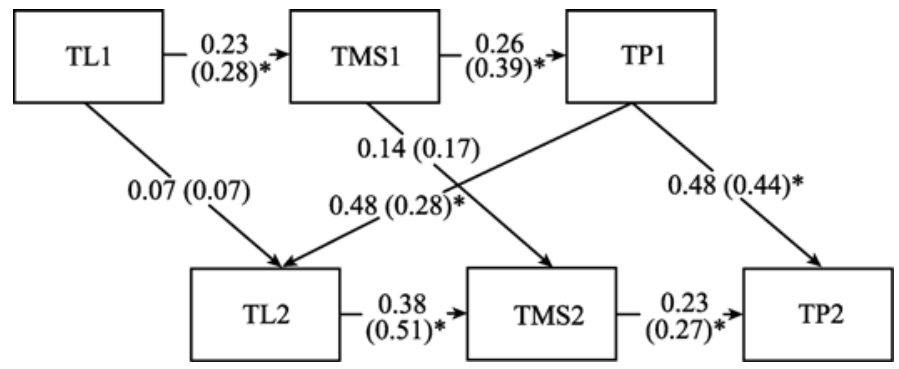

Fig. 1 Longitudinal Path Analysis on Team Learning Performance Mechanism

Note: * indicates significant at level 0.05 . TL means team learning, TMS means transactive memory system, TP means team performance.

As shown in Fig. 1, TMS has significant mediating effects on the relationship between team learning and team performance at both learning stages. However, team learning at stage one does not significantly affect team learning at stage two (the path coefficient is an insignificant 0.07). There is also no significant relationship between the two stages of TMS (the path coefficient is an 
insignificant 0.14 ). However, the previous stage performance is significantly associated with team learning at the following stage, which indicates that performance mechanism of team learning follows the IMOI approach. The results are consistent with the IMOI model or Marks et al.'s (2001) RP model. Thus $\mathrm{H} 2$ is supported. In addition, we notice that the path coefficient between the two stages of performance is also significant, indicating that our conclusion of learning performance mechanism is still incompletely explained.

\section{Conclusion and Discussion}

As an effective approach to facilitate knowledge sharing, communication and innovation, team learning has been widely used in modern organizations. In this study, our basic contention is to illustrate the effectiveness mechanism of learning process by examining the interactive relationship between team learning, TMS, and team performance.

Results show that TMS mediates the relationship between team learning and outcomes. Team learning theory has been largely extended by recognizing the significant effect of TMS in improving learning performance. Knowledge learned by individual team member can be reorganized and distributed to other members by internal TMS. As an effective team knowledge processor, TMS has become increasingly important as learning process gradually develops.

Based on an IMOI approach, results of longitudinal analysis reveal that team learning is a continuous dynamic process. Learning behaviors at the following stage are influenced by the outcome of previous team learning stages. In other words, team learning is not a linear process, but a continuous, non-linear one. In the light of this study, we suggest that the IMOI model proposed by Ilgen et al. (2005) is useful in understanding organizational learning process and mechanism. As shown in Fig. 1, the previous stage performance significantly influences learning process at the following stage, and this phenomenon cannot be well interpreted with the I-P-O model. We thus argue that the IMOI model is better than the traditional I-P-O model in achieving high ecological validity and generalizability for organizational behavior studies with dynamic properties.

The TMS-learning framework developed by Lewis et al. (2005) shows that a TMS produces cycles of learning, and learning transfer is facilitated by the TMS. Based on their cycled causal model, we further suggest that TMS cannot influence the following cycle of learning without the mediating effect of the previous stage outcomes. Thus, we propose a new team learning framework of "team learning-TMS-team performance-team learning" in an IMOI approach.

Several theoretical understandings and practical implications are obtained from the present study. Briefly, the results suggest that developing and maintaining TMS is critical to achieving team outcomes under a team learning 
setting. In addition, performance evaluation and feedback are also important factors within team learning process in a time series framework. Particularly, in the Chinese cultural context, people are concerned about feedback from their supervisors. Praise or awards on their previous outcomes, to a large extent, can encourage team members to do more contributions in the future work.

Several limitations of this paper provide a starting point for further research. First, due to the nature of our data set, we cannot draw strong conclusions regarding the generalizability of the results. Second, although we collected data from different sources in order to minimize common method bias in our analysis, we still applied subjective questionnaires to measure TMS. As a team-level cognitive concept, TMS should be better measured by applying mature cognitive evoked technology in future research.

Acknowledgments This work is supported by the National Natural Science Foundation of China (No. 70602015, 70732001), and the Doctoral Fund of the Ministry of Education of China (No. 20060335127).

\section{References}

Austin J R (2003). Transactive memory in organizational teams: The effects of content, consensus, specialization and accuracy on team performance. Journal of Applied Psychology, 88(5): $866-878$

Bliese P D (1998a). Team size and measure of team-level properties: An examination of eta-squared and ICC values. Journal of Management, 24(2): 157-172

Bliese P D (1998b). Team size, ICC values, and team-level correlations: A simulation. Organizational Research Methods, 1: 355-373

Bruhn M Z, Gibson C B (2006). Multinational organization context: Implications for team learning and performance. Academy of Management Journal, 49(3): 501-518

Burke C S, Stagl K C, Salas E, Pierce L, Kendall D (2006). Understanding team adaptation: A conceptual analysis and model. Journal of Applied Psychology, 91(6): 1189-1207

Edmondson A C (1999). Psychological safety and learning behavior in work teams. Administrative Science Quarterly, 44: 350-383

Edmondson A C (2002). The local and variegated nature of learning in organizations: A team-level perspective. Organization Science, 13(2): 128-146

Goodman J S, Wood R E, Hendrickx M (2004). Feedback specificity, exploration and learning. Journal of Applied Psychology, 89(2): 248-262

Guzzo R A, Dickson M W (1996). Teams in organizations: Recent research on performance and effectiveness. Annual Review of Psychology, 47: 307-338

Hirst M, Luckett P F, Trotman K T (1999). Effects of feedback and task predictability on task learning and judgment accuracy. Abacus, 35(3): 286-302

Ilgen D R, Hollenbeck J R, Johnson M, Jundt D (2005). Teams in organizations: From I-P-O models to IMOI models. Annual Review of Psychology, 56: 517-543

James L R (1982). Aggregation bias in estimates of perceptual agreement. Journal of Applied Psychology, 67: 219-229

James L R, Demaree R G, Wolf G (1984). Estimating within-team interrater reliability with and 
without response bias. Journal of Applied Psychology, 69: 85-98

Jarvenpaa S L, Majchrzak A (2008). Knowledge collaboration among professionals protecting national security: Role of transactive memories in ego-centered knowledge networks. Organization Science, 19(2): 260-276

Langfred C W (2007). The downside of self-management: A longitudinal study of the effects of conflict on trust, autonomy, and task interdependence in self-managing teams. Academy of Management Journal, 50(4): 885-900

Lewis K (2003). Measuring transactive memory systems in the field: Scale development and validation. Journal of Applied Psychology, 88(4): 587-604

Lewis K (2004). Knowledge and performance in knowledge-worker teams: A longitudinal study of transactive memory systems. Management Science, 50(11): 1519-1533

Lewis K, Lange D, Gillis L (2005). Transactive memory systems, learning, and learning transfer. Organization Science, 16(6): 581-598

Liang D W, Moreland R, Argote L (1995). Team versus individual training and team performance: The mediating role of transactive memory. Personality and Social Psychology Bulletin, 21(4): 384-393

London M, Polzer J T, Omoregie H (2005). Interpersonal congruence, transactive memory, and feedback processes: An integrative model of team learning. Human Resource Development Review, 4(2): 114-135

Lynn G, Skov R, Abel K (1999). Practices that support team learning and their impact on speed to market and new product success. Journal of Product Innovation Management, 16: 439-454

Marks M A, Mathieu J E, Zaccaro S J (2001). A temporally based framework and taxonomy of team processes. Academy of Management Review, 26(3): 356-376

McCarthy A, Garavan T N (2008). Team learning and metacognition: A neglected area of HRD research and practice. Advances in Developing Human Resources, 10(4): 509-524

Meyvis T, Cooke A D J (2007). Learning from mixed feedback: Anticipation of the future reduces appreciation of the present. Journal of Consumer Research, 34: 200-212

Moreland R L, Myaskovsky L (2000). Exploring the performance benefits of team training: Transactive memory or improved communication? Organizational Behavior and Human Decision Processes, 82(1): 117-133

Offenbeek M V (2001). Processes and outcomes of team learning. European Journal of Work and Organizational Psychology, 10(3): 303-317

Paulus P B, Yang H C (2000). Idea generation in teams: A basis for creativity in organizations. Organizational Behavior and Human Decision Processes, 82: 76-87

Polzer (2002). Capitalizing on diversity interpersonal congruence in small work teams. Administrative Science Quarterly, 47: 296-324

Ryan A (2004). Organizational learning from performance feedback: A behavioral perspective on innovation and change. Administrative Science Quarterly, 49(3): 490-494

Sivasubramaniam N, Murry W D, Jung D I (2002). A longitudinal model of the effects of team leadership and team potency on team performance. Team and Organization Management, 27(1): 66-96

Tasa K, Taggar S, Seijts G H (2007). The development of collective efficacy in teams: A multilevel and longitudinal perspective. Journal of Applied Psychology, 92(1): 17-27

Todorova G, Argote L, Reagans R (2008). Working alone or together? Individual motivation, group identification, and the development of transactive memory systems. Submitted Manuscript

Wegner D M (1987). Transactive memory: A contemporary analysis of the team mind, in: 
Mullen B, Goethals G R (eds.), Theories of Team Behavior. New York: Springer-Verlag, $185-208$

Wilson J M, Goodman P S, Cronin M A (2007). Team learning. Academy of Management Journal, 32(4): 1041-1059

Wong S S (2004). Distal and local team learning: Performance trade-offs and tensions. Organization Science, 15(6): 645-656

Zhang Z, Hempel P S, Han Y, Tjosvold D (2007). Transactive memory system links work team characteristics and performance. Journal of Applied Psychology, 92(6): 1722-1730

陈国权, 马萌 (Chen Guoquan, Ma Meng) (2000). 组织学习的过程模型研究 (Studies on the process model of organizational learning). 管理科学学报, 3(3): 15-23

张钢, 熊立 (Zhang Gang, Xiong Li) (2007). 交互记忆系统研究回顾与展望 (Transactive memory system research: Review and prospect). 心理科学进展, 15(5): 840-845

张钢, 熊立 (Zhang Gang, Xiong Li) (2008). 交互记忆系统与团队任务、成员异质性、团 队绩效关系的实证研究 (Empirical analysis on relationship between transactive memory system and team task, member heterogeneity and team performance). 技术经济, 27(5): 26-33

张志学, Hempel P S, 韩玉兰, 邱静 (Zhang Zhixue, Hempel P S, Han Yulan, Qiu Jing) (2006). 高技术工作团队的交互记忆系统及其效果 (Transactive memory system in work teams from high technology firms and its consequences). 心理学报, 38(2): 271-280 